\title{
Frequency of W24X Gene Polymorphism among the Students from Hearing Impaired Schools of Shimoga District
}

\author{
https://doi.org/10.47210/bjohns.2021.v29i2.436
}

Gangadhara KS, ${ }^{1}$ Geetha Bhaktha, ${ }^{2}$ Manjula $B^{2}$

Introduction

\section{ABSTRACT}

An important accompaniment of Non-syndromic sensorineural hearing loss is family history and consanguinity. One of the widely studied single nucleotide polymorphism is the gap junction protein beta-2 (GJB2) gene which encodes the protein connexin26. This study aims to detect the frequency of W24X mutation in a population with non-syndromic sensorineural hearing loss concerning the degree of consanguinity.

\section{Materials and Methods}

The study includes 76 subjects with Non-syndromic sensorineural hearing loss. These subjects had congenital sensorineural hearing loss and other causes for the same had been ruled out. The SNP rs 104894396 was identified by the PCR-RFLP method.

\section{$\underline{\text { Results }}$}

The frequency of the wild allele was $0.84 \%$ and the mutant allele was $0.15 \%$. The frequency of wild allele and mutant allele did not differ much between patients with and without consanguinity. The association between consanguineous marriage and allele frequency was not significant. Gene polymorphism was not present in 77 percent of our NSHL subjects, though 79 percent of our study population were a result of consanguineous marriage.

\section{Conclusion}

Though the role of consanguineous marriages in congenital sensorineural hearing loss is well established, the association between allele frequency and consanguineous marriage was not seen. We assume that other genes responsible for deafness may be involved in the population.

$\underline{\text { Kevwords }}$

Hearing Loss, Sensorineural; Consanguinity; Polymorphism, Single Nucleotide; GJB2 protein, human; W24X; Connexin 26

$\mathrm{T}$ The most common neurosensory defect is hearing loss. World Health Organization in its newsroom has reported that 5 percent of the world's population or 466 million people worldwide is known to have disabling hearing loss and among which nearly 34

1 - Department of ENT, Mc Gann's Teaching District Hospital, Shivamogga, Karnataka

2 - Department of Multidisciplinary Research Unit, Shimoga Institute of Medical Science, Shivamogga, Karnataka

\section{Corresponding author:}

Dr Gangadhara KS

email: mrushivamoga@gmail.com million of these are children. Probably by 2050 over 900 million people are slated to have disabling hearing loss. ${ }^{1}$ The majority of the causes of hearing loss are genetic; non-genetic causes may be complications at birth, certain pre-natal infections like Rubella, chronic ear infections, the use of ototoxic antibiotics (e.g., aminoglycosides), exposure to excessive noise, and aging.

Sensorineural deafness or sensorineural hearing loss (SNHL) may be due to aetiologies in the cochlea and the auditory nerve or damage in the auditory pathway.

Sensorineural hearing losses may be classified as acquired and inherited. Deafness is observationally and genetically diverse. When the auditory function is the only observational finding without being associated 
with other symptoms or anomalies it is called the non-syndromic form of deafness. Factors associated with non-syndromic hearing loss (NSHL) are genetic and are due to inheritance. Consanguineous marriage will bring closer the biological association between parents. Hence the probability of their offspring getting the defective gene is more. The relationship between consanguinity and genetic conditions with health problems is extensively known. Some examples are phenylketonuria (PKU), immunodeficiency disorders, beta-thalassemia, and Down's syndrome

Syndromic and non-syndromic hearing loss account for nearly $50 \%$ of the inherited cases. ${ }^{2}$ Of these 70 percent are non-syndromic and 30 percent are syndromic cases of deafness. A major share of loci in the aetiology of nonsyndromic hearing loss has been recognized. ${ }^{3,4}$

Connexin, a four-pass transmembrane protein constitutes the gap junction, which allows intercellular communication. A polymorphism in the GJB2 gene located on chromosome 13q.12 results in the modification of connexin 26 proteins..$^{5}$ It is observed that the genetic cause for congenital deafness is a mutation in the GJB26. W24X is the mutation found in the gene encoding connexin 26. Though there are several mutations associated with hearing impairment and identified in the GJB2 gene, the one common among them was W24X6.

It is observed that most of the cases show clinical features of bilateral hearing loss and are due to either a single monogenic point or small indel mutation..$^{7-10}$ The most observed cause for hearing loss has a strong genetic inheritance and consanguinity plays a major role in it. A common tradition of consanguineous marriage is prevalent among Africans, Asians, and Latin Americans. This results in siblings with a higher incidence of genetic disorders including hearing impairment. It is seen that offsprings of consanguineous marriages run a higher chance of having hearing impairment since the parents are more likely to be homozygous for the trait, resulting in the passing of the defective gene to their children. A family history of deafness is considered a less prevalent risk factor that is closely linked with consanguinity. Hence we aimed to map the prevalence of consanguinity and family history to show the pattern of genotype in hearing loss due to W24X polymorphism.

\section{Materials and Methods}

Selection of study group: A total of 76 subjects were included in the study (47 male and 29 female). In this prospective study, subjects were selected after audiological evaluation. Patients having conductive hearing loss, syndromic hearing loss, history of taking ototoxic drugs, history of otorrhea, head trauma, meningitis, NICU admissions, kernicterus, any other perinatal pathology, maternal complications during pregnancy, or history of maternal consumption of ototoxic drugs during pregnancy or any other known causes of hearing loss were excluded from this study.

Study subjects showing a severe-to-profound congenital hearing loss on pure-tone audiometry were further subjected to immittance audiometry, otoacoustic emissions, and evoked auditory brainstem response evaluation. The study data represents information conducted over one year (January to December 2020).

The non-syndromic congenital sensorineural hearing loss (SNHL) for GJB2 mutations was screened at the speech and hearing center of Shimoga Institute of Medical Science, Shivamogga, Karnataka, India

Blood sample collection: $3 \mathrm{ml}$ of venous blood was collected in an EDTA containing vacutainer tube from the study group with informed consent and was used for DNA isolation.

Genomic DNA isolation: HiPurA Blood Genomic DNA Mini Purification Kits from Himedia PVT was used. This kit provides silica-membrane-based DNA purification from fresh, old (more than 24 hours) and frozen blood. The protocol involves blood cell lysis, which is achieved by incubating whole blood in a solution containing chaotropic ions in the presence of Proteinase $\mathrm{K}$ at $55^{\circ} \mathrm{C}$. The lysate is prepared for the initial binding of DNA to the spin column, and impurities like proteins, polysaccharides, low molecular weight metabolites, and salts are removed by short washing steps. HiMedia's spin column format allows rapid processing of multiple numbers of samples in various volumes. The columns have a high binding capacity and high-quality DNA is obtained which is suitable for downstream processes.

The concentration and purity of DNA were revealed using the Eppendorf micro Cuvette G1.0 
Table I: Demographic data of the study population [N(\%)]

\begin{tabular}{|c|c|c|}
\hline \multirow{2}{*}{ Gender } & Male & $47(61.8)$ \\
\cline { 2 - 3 } & Female & $29(38.2)$ \\
\hline \multirow{2}{*}{$\begin{array}{c}\text { Family history of } \\
\text { deafness }\end{array}$} & Yes & $19(25)$ \\
\cline { 2 - 3 } & No & $57(75)$ \\
\hline \multirow{3}{*}{$\begin{array}{c}\text { Relation with the } \\
\text { deaf individual }\end{array}$} & No relation & $16(21)$ \\
\cline { 2 - 3 } & First & $39(51.3)$ \\
\cline { 2 - 3 } & Second & $5(6.7)$ \\
\cline { 2 - 3 } & Third & $16(21)$ \\
\hline
\end{tabular}

BioSpectrometer basic. The DNA was aliquoted and stored at $-20^{\circ} \mathrm{C}$.

Polymerase chain reaction-restriction fragment length polymorphism (PCR-RFLP): On confirming the purity of DNA, PCR was carried out for 50microliter reactions using Himedia Taq mixture for 40 cycles (each cycle of $94^{\circ} \mathrm{C}$ for 30 seconds, $60^{\circ} \mathrm{C}$ for 30 seconds, and $72^{\circ} \mathrm{C}$ for 60 seconds). The genomic region around the W24X polymorphism was amplified using the desalted primers Forward 5'-TCT TTT CCA GAG CAA ACC GC-3' and Reverse 5'-GAC ACG AAG ATC AGC TGC AG-3' from Metabion International Agency, Germany by Hysel India Pvt Ltd. The amplified DNA fragment was detected by running the PCR product on $1 \%$ agarose gel, electrophoresed at $110 \mathrm{~V}$. A visual quantification of amplified DNA product was done in a gel doc (BioRad) using a 1500 base pair DNA ladder (Himedia). The DNA was then considered for PCR-RFLP procedure. The 286 base pair PCR product was subjected to overnight digestion with AluI restriction enzyme, as per the protocol from the manufacturer's instructions of New England Biolabs.

If the DNA has the mutation, then restriction enzymes will cut the DNA, resulting in fragments of different sizes. The subjects with no mutation in the DNA of interest will not be cleaved, resulting in a single band (286 bp). When the DNA has a mutation in both the strands then the restriction enzyme will cut both the strands resulting in two fragments of equal size, i.e., with two bands as homozygous (182,104 bp).

When the mutation in the DNA is seen only in one
Table II: Genotype data for the W24X mutation in the patients studied $(\mathrm{N}=76)$

\begin{tabular}{|l|c|c|}
\hline No mutation(GG) & 59 & \multirow{2}{*}{$\mathbf{G}=0.84$} \\
\cline { 1 - 2 } Homozygous(AA) & 6 & $\mathrm{~A}=0.15$ \\
\hline Heterozygous(GA) & 11 & \\
\hline
\end{tabular}

strand then the restriction enzyme will cut only that mutated strand. Resulting in a total of three fragments. Hence three bands as heterozygous $(286,182,104 \mathrm{bp})$ are seen.

For analysis, the data was entered in an excel sheet, and frequency in percentage was calculated based on the genotype.

\section{Results}

The study comprised 76 subjects and was fulfilling the inclusion criteria. Among the subjects in our study population, non-syndromic sensorineural hearing loss was higher among the male population. The surprisingly major share of the subjects (75 percent) of the study population had no family history of deafness. Out of the individuals with a family history of deafness, the firstdegree relation with the deaf individual was higher than the not related status. (Table I)

The polymorphism in the W24X gene is depicted in Table II. The allele frequency of the wild gene was higher throughout the study population. Nearly 77 percent of the study population had no gene polymorphism. Among the individuals with the mutation, the homozygous state was less prevalent than the heterozygous state.

The distribution of consanguinity and its genotype data is depicted in Table III. It is seen that 79 percent of this study population were offsprings of consanguineous marriages. Among these, a majority had no gene polymorphism in the W24X gene though having nonsyndromic sensorineural hearing loss. It was observed that there was no difference in risk allele frequency between consanguineous and unrelated marriages.

Figure 1 shows different banding patterns after subjecting to Restriction digestion Alu I. Lane 2 shows the single band of $286 \mathrm{bp}$, lane 3 shows two bands of 
Table III: Grouping of type of marriage with genotype data analysis

\begin{tabular}{|c|c|c|c|c|}
\hline GENOTYPE & UNRELATED N(\%) & CONSANGUINEOUS N(\%) & OR (95 \% CI) & P-VALUE \\
\hline GG & $13(81.25)$ & $46(76.6)$ & & \\
\hline GA & $2(12.5)$ & $9(15)$ & $1.27(0.24$ to 6.63) & $0.78 N S$ \\
\hline AA & $1(6.25)$ & $5(8.4)$ & $1.41(0.15$ to & $0.76 N S$ \\
\hline
\end{tabular}

184, 104 bp, lane 4 shows three bands of 286, 184, $104 \mathrm{bp}$.

\section{Discussion}

The gene encoding for connexin26 is GJB2 (Cx26). This was the first gene found to be associated with an autosomal recessive form of hearing loss. ${ }^{11}$ Most cases of inherited hearing loss also have some other impairment. In our study, we ruled out Usher syndrome, Jaervell Lange-Nielsen syndrome, and Pendred syndrome which were the most frequent associated forms. ${ }^{12}$ We also ruled out prenatal and perinatal factors responsible for NSHL.

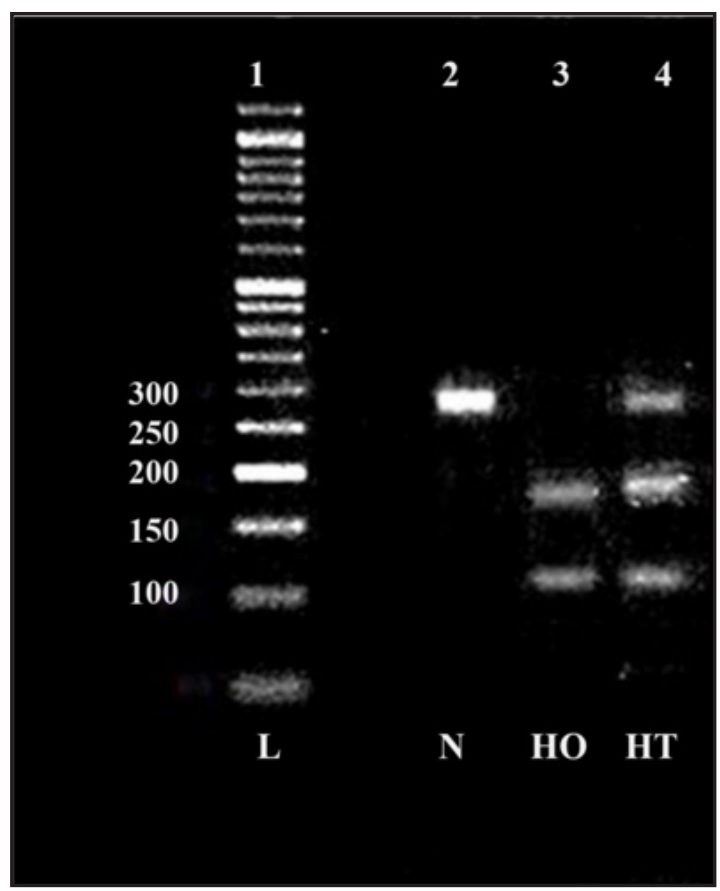

Fig. 1. Agarose gel electrophoresis showing banding pattern.
Non-syndromic forms account for a fair proportion of cases of deafness. This is described as molecular heterogeneity. ${ }^{13}$ There are several ways of inheriting this deafness. In our study, we have focused on autosomal recessive non-syndromic hearing loss. Among these, the mutation in GJB2 which is commonly associated with autosomal recessive forms in the Indian population is W24X. ${ }^{14}$

The prevalence of mutation W24X in India is around 83-96 percent. ${ }^{6,14}$ The demographic data on the prevalence of Non-syndromic hearing loss and their related spectrum of genetic subtypes is very crucial to improve the status of the individual. This mutation affects the gap junction protein in the region where it codes for tryptophan, which on mutation becomes stop codon (W24X).

Across the Indian subcontinent, the identification of this variant has been reported very well. A $26 \%$ frequency rate was reported by Nayar et al from Pune region. ${ }^{15}$ Ramshankar et al have reported an $18.1 \%$ prevalence among congenitally deaf persons. ${ }^{6}$

This study has focused on the difference in the association between consanguinity and risk allele frequency in the subjects of non-syndromic hearing loss. A study from Saudi Arabia had reported that offsprings of consanguineous marriage had a significantly elevated incidence of autosomal recessive disease. ${ }^{16}$ Consanguineous marriage is a common practice in the Middle East and a study conducted by Aljohara et al on the prevalence of the inherited disorder has shown that the incidence of having more than one child with SNHL among the children from a consanguineous marriage is 3.5 times higher than that of a non-consanguineous marriage. ${ }^{17}$ In our study, the prevalence of SNHL among consanguineous offsprings was not significant, though this study had a higher number of siblings 
from consanguineous marriage $(79 \%)$. Connexin channels (gap junctions and hemichannels) are common offenders in a sensorineural hearing loss since cochlear homeostasis is very much needed for hearing. The effect of consanguinity on cochlear morphology has been questioned and speculated to be altered. But consanguineous marriage has not resulted in any structural anomaly of cochlea. ${ }^{18}$ Genetic testing in these offsprings need not be extensive and thus we can limit it to the selective screening of those genes responsible for the functioning of the cochlea rather than its anatomical development. Our study has tried to identify those genes which need to be specifically screened.

We also found 21 percent SNHL among nonconsanguineous marriages. This may be because assortative mating comparatively influences recessive mutations in the general when expressed in a population. ${ }^{19}$

In our study population, $77 \%$ had no gene polymorphism in the W24X gene. This may be because genetic causes of hearing loss are quite heterogeneous. Several studies have shown the presence of some common mutations among the Asian populations. This includes 235delC among the Korean and Japanese population. ${ }^{20-21}$ The mutations W24X and W77X were found in Pakistani and Indian population ${ }^{20-21}$ along with Q124X. ${ }^{22}$ Hence this may be the reason that in our study population other mutations may co-exist with W24X. We assume that other genes responsible for deafness may be involved in the population.

\section{Conclusion}

This study found gene polymorphism for the W24X gene only in 23 percent of subjects. Since the offsprings of consanguineous couples were more, we expected gene polymorphism of this gene to be more prevalent. This shows the possibility of the presence of mutation other than W24X. Further research is needed to identify other unknown mutations for SNHL.

\section{Acknowledgements}

The authors acknowledge the Department of Health
Research, New Delhi, India for providing the facilities at the Multidisciplinary Research Unit for the study. We thank Mr. Geethesh and Mrs. Nirupama, audiologists for helping through the study. Special thanks to Mrs. Revathy, Biostatican for assisting through the statistical analysis.

Funding: This work was supported by the grant from Rajiv Gandhi University of Health Sciences, Karnataka, Project Code: M030, Approved in FY 2016-17.

Conflict of Interest: None declared

Ethical approval: The study was approved by the Institutional Ethics Committee,Ref. No.: SIMS/ IEC/214/2015-16

\section{References}

1. https://www.who.int/news-room/fact-sheets/detail/deafnessand-hearing-loss

2. Alemi AS, Lustig LR. Genetic Sensorineural Hearing Loss. In: Kountakis S.E. (eds) Encyclopedia of Otolaryngology, Head and Neck Surgery. Springer, Berlin, Heidelberg. 2013;3:23498506

3. Minarik G, Tretinarova D, Szames T, Ka dasi L. Prevalence of DFNB1 mutations in Slovak patients with nonsyndromic hearing loss. International Journal of Pediatric Otorhinolaryngology 2012; 76(3), 400-03

4. Van Camp G, Smith RJH. Hereditary Hearing Loss Homepage. https://hereditaryhearingloss.org. [Online]

5. Grillo AP, de Oliveira FM, de Carvalho GQ, et al. Single nucleotide polymorphisms of the GJB2 and GJB6 genes are associated with autosomal recessive nonsyndromic hearing loss. Biomed Research International 2015:19;1309-16

6. Ram Shankar M, Girirajan S, Dagan O, Ravi Shankar HM, et al. Contribution of connexin26 (GJB2) mutations and founder effect to non-syndromic hearing loss in India. J Med Genet. 2003; 40(5):e68

7. American Academy of Audiology Clinical Practice Guidelines: Evidence-Based Best Practice Guideline for Adult Patients with Severe-to-Profound Unilateral Sensorineural Hearing Loss; June 2015

8. Shearer AE, DeLuca AP, Hildebrand MS, Taylor KR, et al. Comprehensive genetic testing for hereditary hearing loss using massively parallel sequencing. Proc Natl Acad Sci U S A. 2010;107(49):21104-09

9. Hoang Dinh E, Ahmad S, Chang Q, Tang W, et al. Diverse deafness mechanisms of connexin mutations revealed by studies using in vitro approaches and mouse models. Brain Res. 2009; 1277:52-69

10. Hilgert N, Smith RJH, Van Camp G. Forty-six genes causing 
nonsyndromic hearing impairment: which ones should be analyzed in DNA diagnostics? Mutat Res. 2009; 681(2-3):18996

11. Kelsell DP, Dunlop J, Stevens HP, Lench NJ, et al. Connexin 26 mutations in hereditary non-syndromic sensorineural deafness 1997; 387:80-3

12. Toriello HV, Reardon W, Gorlin RJ, eds clinical characteristics of hereditary hearing loss and deafness, New York: Oxford University Press; 2004; 4:162-71

13. Shearer AE, Hildebrand MS, Smith RJH. Hereditary Hearing Loss and Deafness Overview. Genet Med. 2007; 9(7):393-408

14. Maheshwari M, Vijaya R, Ghosh M, Shastri S, et al. Screening of families with autosomal recessive non-syndromic hearing impairment (ARNSHI) for mutations in GJB2 gene: Indian scenario. Am J Med Genet A. 2003; 120A(2):180-4

15. Nayyar SS, Mukherjee S, Moorchung N, James E, et al. Connexin 26 mutations in congenital SNHL in Indian population. Indian journal of Otology 2011;17(4): 145-8

16. Zakzouk S. Consanguinity and hearing impairment in developing countries: a custom to be discouraged. J Laryngol Otol. 2002; 116(10):811-6
17. Almazroua AM, Alsughayer L, Ababtain R, Al-Shawi Y, Hagr AA. The association between consanguineous marriage and offspring with congenital hearing loss. Annals of Saudi Medicine 2020; 40(6):456-61

18. Kavitha Y, Sabarigirish K, Joish UK, Saxena S, Dutta A. A study of effect of consanguinity on cochlear morphology in patients with congenital bilateral profound sensorineural hearing loss. Indian J Otolaryngol Head-Neck Surg.2017; 69(4) :483-7

19. Amritkumar P, Jeffrey JM, Chandru J, Kalaimathi M, et al. Role of DFNB1 mutations in hereditary hearing loss among assortative mating hearing impaired families from South India. BMC Medical Genetics 2018; 19(1):105

20. Fuse Y, Doi K, Hasegawa T, Sugii A, et al. Three novel connexin 26 gene mutations in autosomal recessive non-syndromic deafness. Neuroreport 1999; 10(9):1853-7

21. Park HJ, Houn Hahn S, Chun YM, Park K, Kim HN Connexin26 mutations associated with nonsyndromic hearing loss. Laryngoscope 2000; 110(9):1535-8

22. Scott DA, Kraft ML, Carmi R, Ramesh A, et al. Identification of mutations in the connexin 26 gene that cause autosomal recessive nonsyndromic hearing loss. Hum Mutat. 1998; 11(5) :387-94. 